\title{
The role of rose hip (Rosa canina $L$ ) powder in alleviating arthritis pain and inflammation - part II animal and human studies
}

This article was published in the following Dove Press journal:

Botanics: Targets and Therapy

4 May 2016

Number of times this article has been viewed

\section{Kristian Marstrand Joan Campbell-Tofte ${ }^{2}$ \\ 'Department of Orthopaedic Surgery, Elverum Hospital, Elverum, Norway; ${ }^{2}$ Coordinating Research Unit, Frederiksberg University Hospital, Frederiksberg, Copenhagen, Denmark}

\begin{abstract}
Rosa canina fruits (often known as rose hip) have been used in herbal remedies since ancient times. On the basis of anecdotal reports about the effects of rose hip preparations on human health and citations to the same in ancient texts, in vitro and in vivo studies have been conducted that have made it possible to learn about some active ingredients in rose hip, as well as how the component compounds might exert their effects. From such studies, it has been documented that there is a great variation in active ingredients when comparing different rose hip products. Factors which affect the quality and quantity of active ingredients in the rose hip products include the subspecies of the particular $R$. canina from which the fruits are harvested, the environment during plant growth, time of harvesting, and the amount of seeds and shells/husks incorporated into the preparation. Studies in animals and in humans are of great importance for determining the true bio-effects of rose hip. Such in vivo studies that have only been performed during the last 2 decades indicate that the treatment of patients with different types of joint disease with rose hip powder based on a subspecies of $R$. canina (Lito) containing a certain galactolipid (GOPO) can alleviate pain, improve daily activity, and even reduce the consumption of regular pain relievers. As several rose hip components have been shown to be anti-inflammatory, it is suggested that anti-inflammatory mechanisms might explain some reductions in symptoms associated with administering rose hip to arthritic conditions. Although the number of publications of randomized and placebo-controlled clinic studies with rose hip is small, the overriding evidence is that the anti-inflammatory effects from administration of rose hip preparations containing both shells and seeds are superior to preparations containing shells alone.
\end{abstract}

Keywords: physical activity, stiffness, antioxidants, anti-inflammation, quality of life, herbal remedies, dog rose

\section{Introduction}

The known active ingredients in rose hip and relevant in vitro studies designed to investigate their nature and effects were summarized in a recent review. ${ }^{1}$ The main conclusion was that flavonoids and fatty acids are the most interesting molecules when considering the relevance of rose hip in the treatment of patients with inflammatory diseases, such as osteoarthritis. Differential in vitro anti-inflammatory reactions with rose hip extracts made with extractants of increasing polarity indicate that, although some anti-inflammatory properties can be accounted for by the already known compounds, there may be some other active ingredients of great value that are still not known. ${ }^{1}$ As certain flavonoids and the fatty acids are only, or mainly, found in the seeds of rose hip, "the fruit" or so-called pseudofruit, ${ }^{1}$ it is important to distinguish
Correspondence: Kristian Marstrand Department of Orthopaedic Surgery, Elverum Hospital, Kirkeveien 31, 2409 Elverum, Norway Tel +47 405I 3536 Email dr.marstrand@icloud.com 
between a rose hip powder based on shells alone, as opposed to powders based on seeds and shells (Figure 1). ${ }^{1}$

Here, we review studies dedicated to investigating the effects of rose hip preparations on inflammation and pain in animals and humans. The focus will be on how the treatments with rose hip affect pain, daily activity, and inflammation. Yet, there will also be some critical evaluations of study designs, as well as the prerequisite and the importance of placebo-controlled studies. The human studies are considered in two sections, namely open and placebo-controlled studies. Finally, the pros, cons, and main outcomes of the human studies will be discussed.

\section{Animal studies with preparations of rose hip}

Animal studies have the unique advantage that they provide the possibility of obtaining any organ or tissue sample from sacrificed animals during scientific evaluations. In addition, the impact of placebo is less when testing medicines, as compared with the placebo effect that is evident with subject measurements in human clinical trials.

\section{Rose hip studies in mice: anti- inflammatory and antinociceptive screening}

A group of Turkish scientists from Gazi and Yeditepe University were the first to publish data about anti-inflammatory and antinociceptive principles in rose hip extracts tested on experimental animal models. ${ }^{2}$ Anti-inflammatory activity was estimated using the carrageenan-induced hind paw edema model, the difference in foot pad thickness between the right carrageenan infused and left (no infusion) foot was measured and gave the magnitude of anti-inflammatory activity. ${ }^{3}$ Antinociceptive activity was estimated using the p-benzoquinone-induced abdominal constriction test - the number of constrictions giving the amount of pain. ${ }^{4}$ Firstly, rose hip extracts were made by applying organic solvents to rose hip powders. The extracts which showed anti-inflammatory and pain-relieving properties in mice were identified. Then, the active fractions of the extracts were identified through bioassay-guided fractionation procedures. In contrast to the predominantly Danish studies that are mainly based on the Scandinavian rose hip subspecies (Lito) and a powder produced under very controlled conditions, ${ }^{5}$ the rose hip fruits used in the Turkish studies were gathered around the Beytepe Campus area of Hacettepe University in Ankara in September 2004. Whole fruits (containing seeds and shells) were dried under shade and the subsequent activity testing was carried out using two different types of extracts - a warm $\left(60^{\circ} \mathrm{C}\right)$ water extract and an $80 \%$ ethanol extract produced at $40^{\circ} \mathrm{C}$. Preliminary screening of the ethanolic and aqueous extracts for the major groups of phytocompounds like alkaloids, flavonoids, tannins, anthocyanin, anthraquinones, and saponins revealed that the ethanolic extract was by far superior in its phytochemical composition. Hence, the ethanolic extracts were further fractionated through solvent extractions with increasing polarity (dielectric constants) to give the following five fractions: hexane, $\mathrm{CHCL}_{3}$, ethyl acetate (EtOAc), $\mathrm{n}$-butanol $(\mathrm{n}-\mathrm{BuOH})$, and the remaining water fraction.

All the rose hip extracts and fractions were assessed for anti-inflammatory activity in several in vivo experimental models. The original EtOH extract and its EtOAc and n-BuOHs fractions exhibited significant anti-inflammatory activity in carrageenan-induced and $\mathrm{PGE}_{1}$-induced hind paw edema models, as well as on an acetic acid-induced increase in a vascular permeability model. ${ }^{2}$ However, in the carrageenaninduced hind paw edema model, neither of the fractions were as efficient as the mother EtOH extraction, nor was any of the rose hip extract or fractions as efficient as the indomethacin reference anti-inflammatory agent. In the $\mathrm{PGE}_{1}$-induced hind paw edema model, the EtOH extract and its EtOAc and $\mathrm{BuOH}$ fractions also inhibited the inflammatory swellings of the footpad as good as did the reference anti-inflammatory agent, albeit that indomethacin's effect occurred in a shorter timespan. Vascular permeability in tissues is characteristic of inflammatory conditions therein and may also mirror analgesic effects. ${ }^{6}$ The EtOH extract and its fractions statistically significant inhibited the increase in vascular permeability induced by acetic acid, by approximately $30 \%$. The conclusion from the study was that at the dosage of $919 \mathrm{mg} / \mathrm{mL}$, the ethanolic extracts from the "Beytepe" rose hip can reduce inflammation with close to $70 \%$ of what is observed with non-steroid anti-inflammatory drugs (NSAID).

In the Deliorman Orhan et al study, antinociceptive or pain-relieving properties in the rose hip extracts were determined by using the benzoquinone-induced abdominal constriction test. ${ }^{2}$ The antinociceptive activity test is a pain monitoring process used in animal models, which is based on measuring the percentage change in abdominal contraction in response to pain, as compared to that observed in a control group treated with a known antinociceptive agent. The reference compound used in this study was acetyl salicylic acid (ASA). The test is described to be sufficiently sensitive for detecting effects of analgesics less active than acetyl salicylic acid. 
In male Swiss Albino mice, the EtOH extraction, the EtOAc fraction ( $919 \mathrm{mg} / \mathrm{kg}$ per day), and the $\mathrm{n}-\mathrm{BuOH}$ fraction (919 mg/kg per day) all reduced the number of abdominal contractions, although none of them was as efficient as the reference group treated with ASA. The acute inhibitory ratio of the EtOH extract was statistically significant at 27.3 $(P<0.05)$. The inhibitory ratio after subacute evaluation (after 7 days) was 34.7. Similar and statistically significant data were also obtained for the $\mathrm{n}-\mathrm{BuOH}$ and EtOAc fractions. This should be compared to the subacute inhibitory ratio for ASA which was $54.4(P<0.0001)$. Water-based extracts were much less active in this model. It was therefore concluded that EtOAc and $\mathrm{n}-\mathrm{BuOH}$ fractions from $R$. canina offered approximately $40 \%$ of the pain relief observed for ASA in the Swiss Albino mouse model. ${ }^{2}$

Remarkably, all groups treated with $R$. canina extract or fractions thereof were completely free from stomach ulcers, displaying a 0/6 ratio in treated animals. By contrast, the ASA reference group showed a stomach ulcer-affection ratio of 5/6. Interestingly, extractions of whole rose hip or fruits of $R$. canina have earlier been indicated with a strong anti-ulcerogenic potential. ${ }^{7}$ It is also common knowledge that NSAIDs and ASA can cause ulcerations in the gastrointestinal (GI) tract of mammals, while other painkillers such as COX-2 inhibitors (Viox) do not cause GI bleeding. The in vitro studies of Jäger et a $l^{8,9}$ clearly demonstrate that rose hip powder contains components that act mainly as a COX-2 inhibitor. The IC50 value for linoleic acid (mainly present in the seeds) was $0.6 \mu \mathrm{M}$ for COX-2 and $85 \mu \mathrm{M}$ for COX-1, and a similar pattern was observed for alpha-linolenic acid, also mainly present in the seeds. The COX-2/COX-1 ratio of linoleic acid and alpha-linolenic acid was 0.007 and 0.2 , respectively. This support the observations that GI bleedings were absent during treatment with rose hip containing seeds and shells.

The mice data describing the in vivo effects of rose hip extracts derived from both shells and seeds of $R$. canina are in concordance with results of clinical studies with rose hip powder in humans, where neither active treatment nor placebo for 3-6 months caused the development of GI side effects. ${ }^{5,10-12}$

Saaby ${ }^{13}$ also performed a study on the antinociceptive effects of rose hip seed and shell powder in mice, by performing the hot plate test devised by Woolfe and Mac Donald. ${ }^{14}$ In an effort to obtain a broader range of the compounds present in the powder, a solution containing dichloromethane and ethanol extract in the ratio of 1:1 was prepared. Eighteen mice received extracts corresponding to $500 \mathrm{mg} / \mathrm{kg}$ per day for 3 days by oral gavage, while the mice in the control group $(\mathrm{n}=20)$ only received vehicle. There were no significant differences when comparing the two groups, so the dichloromethane-ethanol extract did not contain antinociceptive properties when compared to a control group while using the hot plate model on mice. It is pertinent to note that not only was the dosage used in this experiment lower than what was applied in the study from Deliorman Orhan et $\mathrm{al}^{2}$ but the extraction procedures were also different.

Consequently, the superiority of the EtOH extract tested by Deliorman Orhan et al in protecting against inflammation and pain, when compared to the extraction used by Saaby, ${ }^{13}$ may solely be due to the properties of the extraction solution. ${ }^{2}$ However, there may also have been some problems associated with the aqueous extraction being held at $60^{\circ} \mathrm{C}$, as the heat may have destroyed some active elements in the product. Nevertheless, the Deliorman Orhan et al study ${ }^{2}$ suggests that there are at least two active components with anti-inflammatory and antinociceptive properties in rose hip powder made from whole fruits, one in the EtOAc fraction and one in the $\mathrm{n}-\mathrm{BuOH}$ fraction. Flavonoids and tannins were found to be the dominant constituents of the EtOAc and n-BuOH fractions. The flavonoid rutin, mostly present in rose hip seeds, and quercetin, equally distributed in both seeds and shells, have been reported as having greater anti-inflammatory capacity, as well as possibly protect the GI tract. ${ }^{15}$ Unfortunately, subsequent fractionations and bioassays of the active EtOAc and n-BuOH fractions did not lead to the isolation of definitive constituent(s) with anti-inflammatory and pain-relieving properties, possibly due to a synergistic interaction of components in the extracts. As the authors possibly got some inspiration from studies on humans, in which whole rose hip powders were tested, it would have been interesting if the mice had been administered the whole powdered rose hip fruits, not extracts containing a limited amount of ingredients. Frankly, eating powdered rose hip containing all the natural ingredients of rose hip including fibers may exert some effects in the gut, which are very different from that observed by feeding on a small part of rose hip in the form of extracts.

The cardinal signs of inflammation have long since been known to cause redness, swelling, pain, and heat, as described by Aulus Cornelius Celsus (25 BC-50 AD). The Deliorman Orhan et al study ${ }^{2}$ is particularly interesting as two of the classical inflammatory symptoms - swelling and pain - were evaluated. Later in 2007, independent Danish research substantiated the findings of Deliorman Orhan 
et $\mathrm{al}^{2}$ by demonstrating the impact of $R$. canina compounds on prostaglandins during inflammation. Specifically, the fatty acids linoleic and alpha-linolenic acids from $R$. canina inhibit COX-2 enzyme. ${ }^{8,9}$

It was also interesting to note that the mucosa of the GI tract seemed to tolerate rose hip extracts and their fractions much better than it did NSAID. The observed effects on inflammation, pain, and swelling are further strengthened because a certain element of dose-dependency was noticeably present.

\section{Mice studies: rose hip seeds and metabolism with special reference to obesity}

Ninomiya et $\mathrm{al}^{16}$ reported that an $80 \%$ aqueous acetone extract from seeds of the fruits of $R$. canina significantly suppressed body weight gain after 5-14 days of being administered to mice, without affecting food intake. In addition, the authors found that levels of plasma triglyceride and free fatty acids were significantly reduced after 14 days. The active constituent was identified as tiliroside, which is only found in the seeds of rose hip. ${ }^{16}$ Dose-dependency was evident, as the dosage of $25 \mathrm{mg} / \mathrm{kg} /$ day was found to show an inhibitory effect on the gain of body and visceral fat weight, which was greater than that observed for the dosage of $12.5 \mathrm{mg} / \mathrm{kg} /$ day.

The effect of tiliroside on lipid metabolism promotion was further investigated by monitoring the mRNA expression levels of peroxisome proliferator-activated receptor alfa (PPAR- $\alpha$ ) in liver tissue, using a reverse transcription polymerase chain reaction method. After 24 hours of administering a single dosage of the earlier mentioned compound to mice, the expression of the PPAR- $\alpha$ mRNA levels were significantly increased in the liver tissue, suggesting that tiliroside promotes lipid metabolism. This study was further supported by a randomized, placebo controlled and double-blinded study in humans. Active treatment consisted of $100 \mathrm{mg}$ of rose hip seed extract containing tiliroside for 3 months. ${ }^{17}$ Abdominal visceral fat, body weight, and body mass index were significantly reduced in the active-treatment group. The authors concluded that rose hip seeds may also be useful for the treatment of obesity.

\section{Studies in rats}

Lattanzio et $\mathrm{al}^{18}$ found dose-dependent anti-inflammatory activity of hydroalcoholic $R$. canina extracts in a carrageenaninduced rat paw edema assay, which was comparable to the reference drug, indomethacin. By contrast, Saaby ${ }^{13}$ only found a trend to reducing paw edema 1-5 hours and again
24 hours after treatment of rats with dichloromethane:ethanol (1:1) rose hip extracts. ${ }^{13}$ Only one dosage $(100 \mathrm{mg} / \mathrm{kg})$ was tested in the Saaby ${ }^{13}$ study, and the extraction procedure used (dichloromethane:ethanol extraction) was different to that used by Lattanzio et al. ${ }^{18}$ Hence, it is difficult to compare the Saaby ${ }^{13}$ and Lattanzio et $\mathrm{al}^{18}$ studies, where the higher dose of plant extract ( $200 \mathrm{mg} / \mathrm{kg}$ ) was superior to indomethacin in reducing swelling of the rat paw and the anti-inflammatory effect was evident 30 minutes after administration of the extract, reaching its peak within 1 hour. The anti-inflammatory effect observed in rats by the Lattanzio et $\mathrm{al}^{18}$ study also differs somewhat from previous data reported by Deliorman Orhan et al, ${ }^{2}$ who did not find significant changes in mice paw swellings within the first 180 minutes of administration of the rose hip extract. However, the animal model (mice) used and the extraction procedures for rose hip were different in the Deliorman Orhan et $\mathrm{al}^{2}$ studies.

Lattanzio et al $^{18}$ also detected some gastro-protection from extractions of rose hip seeds in rats subjected to ethanolinduced gastric damage. However, the anti-ulcerogenic effect was not statistically significant. This finding also differs from earlier reports by Deliorman Orhan et $\mathrm{al}^{2}$ and Gürbüz et $\mathrm{al}^{7}$ who found up to $100 \%$ ulcerogenic protection by $R$. canina extracts made from whole fruits containing a combination of seeds and shells.

\section{Studies in horses and dogs}

Race horses and greyhounds that are subjected to intensive training exercises are of interest when considering protection from inflammatory diseases, as oxidative stress has been shown to occur during strenuous exercise. ${ }^{19}$ Oxidative stress has also been implicated in the etiology of a number of equine diseases, including recurrent airway obstruction ${ }^{20}$ and joint disease. ${ }^{21}$ Indeed, a decline in vitamin $\mathrm{C}$ levels in horses is considered an important early sign of stress. However, artificial vitamin $\mathrm{C}$ is poorly absorbed in horses, and it can take up to 3 weeks after starting treatment ( $20 \mathrm{~g}$ per day) before elevation in plasma levels are obtained. ${ }^{22}$ Hence, it is of interest to find ways to feed horses with diets containing high levels of vitamin $\mathrm{C}$ in a form which is more easily absorbed, than what has been available till now.

A randomized and placebo-controlled study of rose hip powder (LitoVet - consisting of seeds and shells) in 44 horses (trotters) for a 3-month period indicated that $R$. canina has the same anti-inflammatory activity in horses ${ }^{23}$ as earlier described for humans..$^{5,10-12}$ Chemotaxis of neutrophils isolated from horses administered rose hip powder was significantly reduced when compared to chemotaxis in 
neutrophils from the horses that received placebo. The rose hip powder also significantly improved the antioxidative capacity when estimated as chemiluminescence using horse neutrophils as a model. The actively treated horses showed statistically significant improvements in their speed measured as a shortening of the time for running a 1,000 $\mathrm{m}$ stretch in $1.1 \pm 1.5$ seconds. Such improvement was not observed in the placebo group. ${ }^{23}$ Moreover, the actively treated horses were more lithe the day after strenuous exercise. Improvements in speed and litheness were accompanied by significant improvements in the horses' plasma vitamin C levels. ${ }^{21}$ Dosedependency was demonstrated in horses, and doses of rose hip powder less than $250 \mathrm{mg}$ daily reduced the liberation of oxidative anions and raised blood levels of vitamin C. ${ }^{24}$

In greyhounds administered the same LitoVet rose hip powder, for 3 months, the dogs were more lithe the day after strenuous exercise, showed improvements in their speed and fur quality as compared to animals of the same age and grain that received placebo. ${ }^{25}$ LitoVet rose hip powder also showed some anti-inflammatory power as the total number of leucocytes significantly declined as a result of 3-month treatment. Such decline was not observed in the placebo group. ${ }^{25}$ In addition, the speed by which dogs were running also improved, $P<0.027 .{ }^{25}$

The overall outcome in horses and dogs are that there are indications that an anti-inflammatory action takes place, that speed can improve as a result of rose hip treatment, and that the animals are more lithe the day after strenuous exercise. The latter observation is interesting as more litheness was also demonstrated in a study in which human volunteers were given rose hip powder for a 6-month period during the winter season (Winther, unpublished data, 2015).

\section{Human studies}

For a proper evaluation of the effects of any investigative medicine in humans and to some extent animals, there is a need for placebo control. This is evident when testing herbal remedies like rose hip powders, whether the preparations be with or without seeds. The effect size (ES) of a remedy cannot be calculated if the impacts of a placebo are not deducted. ${ }^{26}$ It is therefore important to clearly distinguish between open studies and placebo-controlled studies (which are often referred to as blinded studies), as what a researcher gets from an open study will not always be the impact from the new compound, but more the expectations of volunteers to the new remedy. ${ }^{27}$ All the same, open studies are very useful and can provide important guidelines for planning subsequent blinded (placebo controlled) studies, as well as offer hints of the types and severity of side effects to be expected. It is generally agreed that with osteoarthritis, up to $50 \%$ or more of self-reporting patients positively respond to placebo treatment, ie, they practically feel a reduction in their symptoms while on placebo treatment. ${ }^{27}$ Thus, if an open study with investigating the ameliorating effects of an investigative therapy on osteoarthritis does not produce an improvement greater than $50 \%-60 \%$ in positive response rates, it is doubtful if a more complex and expensive placebo-controlled study should be set up. ${ }^{27}$ However, when the open study involves blood sampling and the associated laboratory biochemical analyses of markers like cholesterol and C-reactive protein (CRP), the results may not be influenced to the same levels as would occur if the study depended solely on self-reported symptoms submitted by volunteers on questionnaires. For these reasons, we distinguish between open studies without any placebo control group and clinical studies including placebo control in this review.

There has lately been some focus on two different versions of rose hip powders - firstly, the original version made from milling the whole $R$. canina fruit, ie, a combination of seeds and shell/husks powder. The second and "new" version is based on milling shells/husks of rose hip alone. The latter is reported to be "enhanced" with a so-called "complex" which consists of vitamin C (of which a small part is added artificial vitamin C), flavonoids, carotenes, triterpene acids, and galactolipids. There are some difficulties associated with evaluating the importance and relevance of this "new, complex, and enhanced version" of rose hip preparation because to many researchers vitamin $\mathrm{C}$, flavonoids, carotenes, triterpenoids, and galactolipids are normal constituents of $R$. canina fruits Indeed, by eliminating the seeds which are known to contain important polyunsaturated fatty acids and many important flavonoids, the final product may be "weakened" rather than being "enhanced".

\section{Open studies with rose hip powder in the treatment of osteoarthritis}

The first open study on humans was based on powder from the rose hip subspecies Lito and contained the natural amount of seeds and shells. ${ }^{28}$ The powder was given to eight volunteers (four healthy and four osteoarthritic patients). There was a reduction in CRP as a consequence of treatment. In addition, significant reductions in chemotaxis and chemilumeniscence of polymorphonucleated leucocytes (PMNs) isolated from both healthy and osteoarthritic test subjects were also observed. ${ }^{28}$ By comparison, vitamin $\mathrm{C}$ had no effect on PMNs suggesting that the anti-inflammatory and antioxidative 
capacities of rose hip powder were not dependent on its vitamin $\mathrm{C}$ content. The interesting aspects from the open study was that 1) anti-inflammatory properties of rose hip powder containing the natural amount of seeds and shells was expressed in both healthy and osteoarthritic backgrounds; 2 ) rose hip powder is well tolerated by humans, even when administered in a fairly high dosage (45 g daily for 28 days), and patients with osteoarthritis reported less pain.

The next clinical study that reported the results of testing a rose hip preparation on humans was carried out as follows: 13 healthy volunteers were each treated with $45 \mathrm{~g}$ of rose hip powder daily for 4 weeks, followed by at least 1 month of withdrawal and further treatment with $10 \mathrm{~g}$ rose hip powder daily for a final 4 -week period. ${ }^{29}$ The rose hip preparation used was again based on the natural amount of seeds and shells from a subspecies of $R$. canina (Lito). The fruits were dried by using a special patented drying procedure, which necessitates that the plants be held at temperatures never exceeding $40^{\circ} \mathrm{C} .{ }^{11}$ There was a significant decline in CRP as the result of 4-week treatment with the high dose of rose hip powder, and this finding was supported by a decline in the chemotaxis of PMNs isolated from the study participants and stimulated with the chemotactic peptide f-Met-Leu-Phe (fMLP) or zymosan activated serum.

In the Kharazmi and Winther study, ${ }^{29}$ there were no changes in potassium, sodium, alanine aminotransferase, alkaline phosphatase, lactate dehydrogenase, bilirubin, or hemoglobin levels in the test subjects, indicating that the powder was well tolerated. Rather, there was a small but significant reduction in serum creatinine, which would suggest a beneficial effect of the treatment on kidney diseases as already known from the application of rose hip in folk medicine. It is important to note that the high dose of $45 \mathrm{~g}$ rose hip powder taken daily did not cause any side effects.

In the background of these positive confirmations of antiinflammatory and antioxidative properties of rose hip in vivo, a large open study was carried out to assess its efficacy in reducing pain in arthritic patients. A total of 152 patients, among whom 124 suffered from severe back pain, eleven had pains related to the hip, nine had pains related to the knees, and eight participants with specific lower back pain, took part in the pilot clinical study. ${ }^{30}$ The main objective of the study was to find out if a $R$. canina preparation (again based on the subspecies Lito) containing an equal amount of seeds and shells would reduce acute exacerbations of chronic back pain. The study was on the intention-to-treat basis. The dosage was originally set at $5 \mathrm{~g}$ of a rose hip seed and shell product per day. However, at the first clinic visit of a few patients 6 weeks into the treatment period, the pain level was so high that it was decided to change the study protocol, so that the study participants either took 5 or 10 g per day, depending on the severity and duration of pain they experienced. This means that 148 patients had the choice of taking 5 or $10 \mathrm{~g}$ daily. Clinical symptoms and well-being were tested every 6 weeks during the 1 -year trial period, using questionnaires. Seventy-five patients dropped out during the 1 -year study, and 42 of these patients did so because of insufficient pain release. As such, only 77 patients completed the year of surveillance. The median values on symptom scores (pain) declined to values which were $35 \%-65 \%$ of baseline, and the positive responder rate was a little above $60 \%$. It is difficult to resolve pain symptoms occurring in the lower back. Even though it is interesting to note that many patients, in the present study, responded to treatment positively, it should be brought into mind that approximately $50 \%$ of the participants dropped out of the study and the majority of these because of insufficient pain control. The present study can therefore not document that rose hip works in lower back pain but the study stimulates to further research on the present group of patients. ${ }^{30}$

In addition, the significant decrease in pain, which was first recorded after 3 months of treatment, continued to manifest during the subsequent 9 months of treatment, indicating that pain reduction, whatever the magnitude, continues with long-term rose hip treatment. This is important information, especially as the same observation was made in a study on pain reduction in rheumatoid patients treated with the same rose hip powder for 6 months. ${ }^{5}$

However, it is a disadvantage that the study is not placebo controlled, especially as the investigation involves osteoarthritis patients who are known to positively score high with placebo treatment. ${ }^{27,31}$

A total of 27 patients reported a total of 32 side effects, which were possibly related to the active treatment. However, the types of side effects were not defined. The study lasted for 1 year, and the number of side effects was not in disagreement with the number of side effects reported in placebo-controlled studies that ran for over 3-6 months, where the test group received $5 \mathrm{~g}$ rose hip powder/day. ${ }^{5,10-12}$

In a more recent open study, Chrubasik-Hausmann et $\mathrm{al}^{32}$ tested a rose hip preparation based only on the shells/husks on 52 patients, also suffering from acute exacerbations of low back pain ( $n=39)$ and knee pain ( $n=13)$ for 3 months. Reductions in pain were again accessed using questionnaires, and the study design was the same as used in the earlier study. ${ }^{30}$ Interestingly, reductions in pain and disability scores in this study with the 
shell-based rose hip powder were very similar to the data obtained in the earlier study using the powder made from seeds and shells, but with the important difference that the dose of shell powder needed to give effect sizes comparable to those obtain in the earlier study with the seeds and shell/husks powder was up to three times higher ( $20 \mathrm{~g})$ per day. As both studies are open, it is not easy to calculate the impact(s) of the rose hip powders that is not related to the "placebo effect". Indeed, the effect sizes in these studies may not be that far from what was observed for placebo in other studies on osteoarthritis treatment. ${ }^{27}$ In the rose hip shell-based study, eight adverse events, among these stomach fullness, abdominal pain, diarrhea, stomach pain, and allergic skin reaction were reported, which were likely related to the consumption of the powder.

The most recently published open study was designed to compare the safety and efficacy of the regular seeds and shell rose hip powder with two different doses of a "new version" of shell-alone rose hip powder. ${ }^{33}$ The "new version" of rose hip powder is prepared from milling the emptied husks of rose hip and the resulting powder is further enriched by the "complex" containing added vitamin C, flavonoids, carotenes, triterpene acids, and galactolipids, as earlier outlined in this review. The choice of generating rose hip powder from the shells/husks alone was based on the findings of Wenzig et $\mathrm{al}^{34}$ that the anti-inflammatory and radical scavenging properties in whole rose hip powders may be concentrated in the shells or husks. Hence, 150 patients with osteoarthritis of the knee were randomly assigned to three groups: daily administered $4.5 \mathrm{~g}$ seeds and shell rose hip powder (six capsules), or $4.5 \mathrm{~g}$ rose hip powder prepared from the shells alone (six capsules), or $2.25 \mathrm{~g}$ (three capsules) of the same rose hip shell-powder, respectively. The study was not blinded, as the group taking the low-dose shell-based powder knew that they were on the "enhanced" new version. Efficacy assessments were made with the aid of questionnaires. All three rose hip preparations proved to be equally efficacious, as measured with the pain subscale of the Knee Injury and Osteoarthritis Outcome Score (KOOS), ${ }^{35,36}$ except for one of the secondary parameters "function" in which the lower dose of "new version" was superior to the regular $4.5 \mathrm{~g}$ seeds and shell powder. The higher dosage of the "new version" shells only powder was in an intermediate position, and it was not significantly different from the two other treatments. This observation was interpreted to mean: LESS MEANS BETTER and the overt dose-response curve was invented. Generally, the number of positive responders to the treatments was low, with the lowest being recorded for the $4.5 \mathrm{~g}$ shell powder. With the background of relatively high effect sizes associated with the "placebo effect" in assessments of osteoarthritis treatments, one might then argue that none of the rose hip therapies was particularly effective in the study. The rather strange outcome of this study might also be related to the fact that patients simply preferred to take three capsules instead of six.

A novel outcome of this clinical trial with seed and shell-based powder vs the so-called "enhanced" shell-based powder was that tolerability of the new compound was tested applying a high-quality technique. The test is based on using standardized questionnaires for side effects, which involves systematically interrogating the study participants for nine GI, five musculoskeletal, seven skin, five miscellaneous, seven central nervous and psychiatric symptoms. ${ }^{37}$ Unfortunately, the technique was not used in any of the other clinical trials reviewed here. It is therefore difficult to compare with data from the other rose hip studies that are centered on the total number of patients reporting a particular side effect and in which patients are not actively interrogated about specific side effects. However, it would seem that more patients administered the "enhanced" rose hip powder based on shells experienced more side effects, as compared to the seeds and shell powder group. For example, there were more reports of nausea in both low- and high-dose enhanced rose hip shell powder groups $(P<0.098)$ and more reports of urticaria in the high-dose enhanced rose hip powder group $(P<0.069)$, when compared to the other groups. When the low-dose shell-alone group was compared to the higher $4.5 \mathrm{~g}$ seeds and shell powder group, there were significantly more GI-related side effects in the shells group $(P<0.014)$. This suggests that the seeds may exert some GI protection, as was suggested in the Deliorman Orhan et al studies with different extracts of rose hip in mice. ${ }^{2}$

The Christensen et $\mathrm{al}^{33}$ study is an example of how a complex protocol can lead to the generation of data that are not that easy to interpret. For example, the study could have been easily blinded by adding three placebo capsules to the low dosage shell-only group. The superiority of the low dose of the "new version" as compared to the other two treatments can easily be due to expectations, because the study participants knew that they were on a new version of a well-known and rather popular treatment. Another explanation of the data can simply be that patients prefer to take three instead of six capsules - although this can hardly explain the rather high number of side effects reported during low-dose shell-powder treatment.

The majority of clinical trials involving evaluations of efficacy and safety of rose hip preparations have been aimed 
at osteoarthritic patients. However, evaluations of the efficacy of the herbal preparation against other diseases have been published. For example, a trial has been reported of daily administering $10.5 \mathrm{~g}$ of the whole powder (containing seeds and shell) to 19 patients with rheumatoid arthritis (RA) for 4 weeks. ${ }^{38}$ There were no significant changes in questionnaires on pain and stiffness or alterations in blood levels of CRP in any of the groups. The authors concluded that by comparing the results to other studies with osteoarthritis and RA, the 4-week treatment period may have been too short.

\section{Placebo-controlled and double-blinded clinical studies with osteoarthritic patients}

The first double-blind, randomized and placebo-controlled, parallel clinical trial with rose hip was carried out in 100 male and female patients, all on a waiting list for hip or knee replacement, ie, so-called end-stage osteoarthritis. ${ }^{12}$ The study was based on the intention to treat. A standardized preparation of rose hip powder, based on the subspecies Lito containing the natural amount of seeds and shells or placebo $(5 \mathrm{~g})$, was given daily to the study participants for 4 months. The objective was to assess the impact of the rose hip powder on the mobility of the hip and knee joint, activities of daily living, quality of life, and pain. Mobility measurements included the full range of external and internal rotation of the hip, and maximum flexion and extension of the hip and knee measured using a goniometer (Gallus Plesner, Oslo, Norway). Hip flexion as well as external rotation improved significantly as a result of treatment with rose hip, in comparison to placebo.

The reduction of hip flexion as a result of end-stage osteoarthritis was reduced by approximately $40 \%$ by the rose hip powder as compared to the placebo group $(P<0.033)$ and a similar trend was observed for external and internal rotation of the hip. Active treatment resulted in a significant improvement of knee flexion angle by $2.71^{\circ}(P<0.012)$; however, a similar and statistically significant improvement was observed in the placebo group, with no significant difference when comparing groups. Daily activity scores improved as a result of active treatment, and there was a significant lowering of overall joint pain when estimated after 4 months on a categorical scale from 0 to 4 ( $P=0.035)$ comparing groups. When evaluated on the yes/no basis after 4 months of treatment, $65 \%$ of patients on rose hip reported a reduction in joint pain, as compared to $35 \%$ of patients in the placebo group reporting improvement $(P<0.046)$. Although the study participants were instructed not to change their intake of rescue medication, the actively treated group reduces their consumption of $\operatorname{NSAID}(P=0.016)$, while a slight increase in rescue medicine intake was observed with placebo. There were no significant differences when comparing groups. Two patients in each group dropped out due to reasons not related to the treatments and two patients in each group reported milder GI side effects. In conclusion, the treatment was well tolerated and produced statistically significant benefits to patients in end-stage osteoarthritis.

However, succeeding studies focused more on rose hip treatment of early stages of osteoarthritis, as it would be interesting to determine if the treatment could annul the need for complex surgery. Thus, 112 patients with osteoarthritis of the hand, shoulder, hip, knee, or neck were included in a randomized, placebo controlled cross-over study in which the rose hip powder based on the subtype Lito, containing the natural amount of seeds and shells, or placebo was given for 3 months in the dosage of $5 \mathrm{~g}$ daily, after which the group receiving active treatment was changed to placebo and vice versa. ${ }^{10}$ The primary effect variables were joint pain and possible changes in the consumption of rescue medication. Secondary outcome was joint stiffness, general well-being, mood, energy, sleeping quality, and preference to treatment given. Pain was estimated on a five-step categorical scale from 0 (no alleviation of pain) to 4 (almost total relief of pain). This technique also provided the basis for calculating the responders to treatment and non-responders in each group. Each day the number and type of analgesic consumed was noted in a diary kept by each volunteer. All patients taking NSAIDs regularly on prescription from their general practitioner were advised to continue such treatment. After a total of 3 weeks in each of the two treatment regimens, pain levels in the study subjects were accessed and a recommendation to reduce their consumption of pain relievers was made, if this was considered tolerable. The study was based on the intention to treat. There were fifty six patients in each group at the initiation of the treatment; 16 withdrew during active treatment, while 11 left from the placebo group.

As expected, the group which got placebo first showed significant improvement during the last 3-month period when they were administered the rose hip powder, as compared to the first 3 months on placebo. By contrast, the second group which got active treatment first showed a positive effect of the same order as was observed in the first group for active treatment, and retained the improvement during the treatment with placebo. The same pattern was observed when general levels of well-being were evaluated from the diary records kept by the participants. The data confirm that the rose hip powder not only reduces the symptoms of osteoarthritis, 


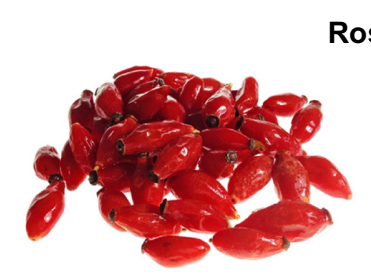

Rose hips

Berries

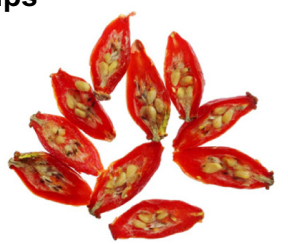

Berries cut

Figure I Ripe frozen berries from Rosa canina $L$. are shown in the left panel and ripe frozen berries cut through with visible seeds are shown in the right panel.

but confers a strong "carry over" effect which remains after cessation of the treatment, as detailed in Figure $2 \mathrm{~A}$ and B. ${ }^{10}$ When calculating the number of patients who responded to active treatment, $66 \%$ responded in the actively treated group whereas $36 \%$ responded in the placebo $(P<0.043)$. This was fairly close to what was observed in an earlier study ${ }^{12}$ that focused on end-stage osteoarthritis. The reduction of consumption of rescue medication such as paracetamol, codeine, and synthetic opioids showed a pattern that is in agreement with that observed for reduced pain.

The secondary effect parameters improved, albeit that improvement in sleeping quality during rose hip treatment may have developed from the patients experiencing less pain and stiffness during the night. The patients' preference to treatment was like wise strongly in favor of active treatment. There were no changes in blood glucose, but active treatment resulted in a significant fall in total blood cholesterol (8.5\%). Although 27 of the original 112 patients dropped out during the 6-month treatment period, only three of these were because of adverse reactions, namely acid regurgitation in one patient receiving placebo and diarrhea in two patients - one from the placebo group and the other from the rose hip group. For the further 24 withdrawals, 12 reported mild unwanted effects such as urticarial, constipation, diarrhea, water brash, and frequent micturition. As all mild unwanted side effects were experienced equally by study subjects from both active and placebo groups, the Lito-based rose hip powder seems to be well tolerated.

A subsequent sub-study performed on the patients from the Rein et $\mathrm{l}^{10}$ study, who reported osteoarthritis (OA) of the dominant hand, showed that $90 \%$ of the subgroup reported reductions of pain in the hand while on active treatment. Active treatment also resulted in a reduction in the consumption of rescue medication. This means that even when the larger group of $112 \mathrm{OA}$ patients are reduced to 30 patients with OA of the dominant hand, there is still a statistically significant reduction of the consumption of pain killers. ${ }^{39}$

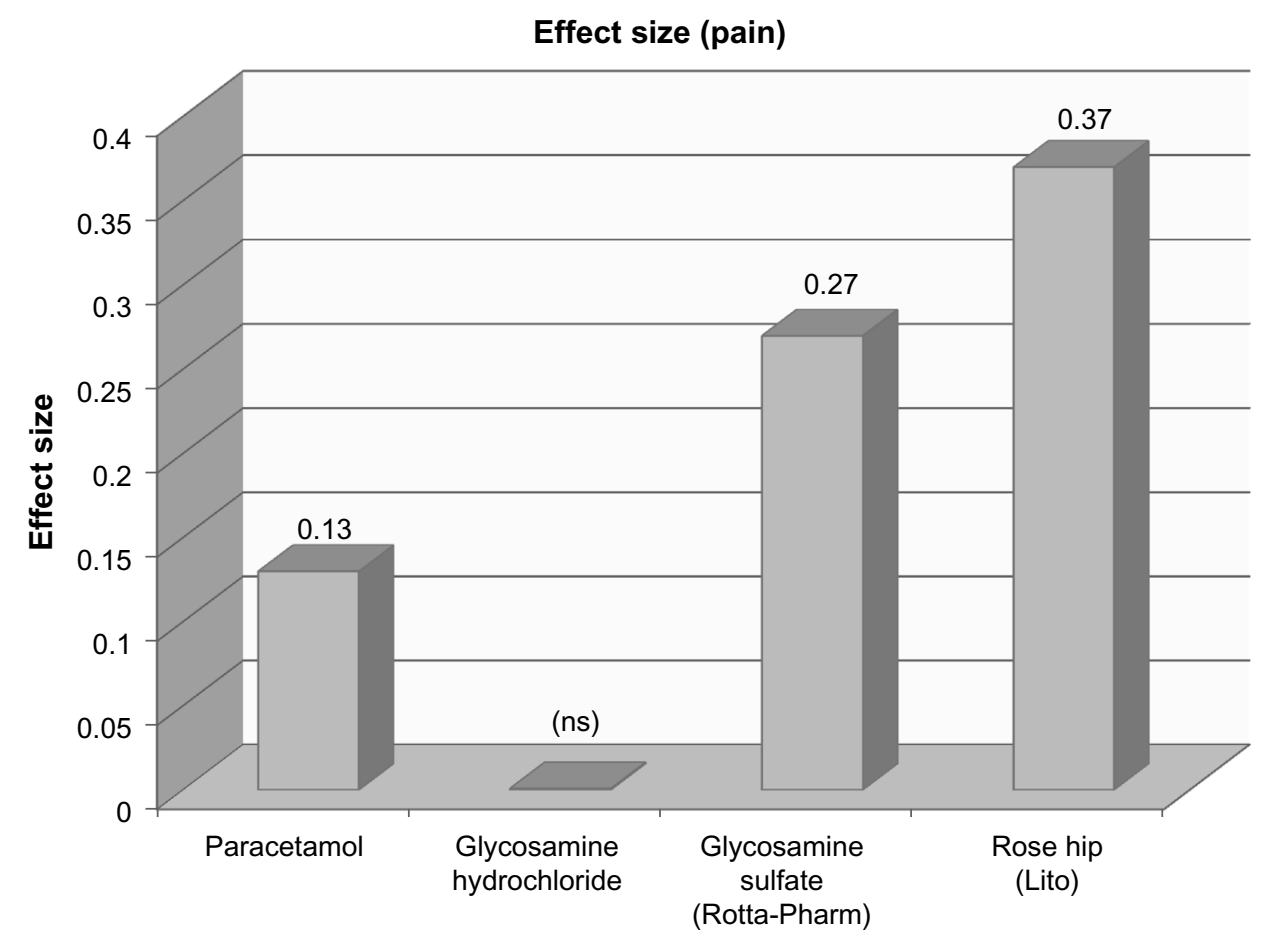

Figure 2 Effect size of paracetamol, glucosamine, and rose hip on pain is given.

Note: Data extracted from Christiansen et al. ${ }^{26}$

Abbreviation: ns, not significant. 
In another randomized, double-blind, placebo-controlled, cross-over study, $5 \mathrm{~g}$ (daily dose) of the Lito rose hip powder was tested on 94 patients diagnosed with early stages of osteoarthritis in the knee or hip. ${ }^{11}$ In this experiment, the Ontario and McMaster Universities (WOMAC) osteoarthritis inde ${ }^{40}$ was used for accessing joint pain. The WOMAC score of joint pain together with the analgesics taken during the two different treatment periods was the main outcome measures, whilst the secondary outcome measures were the scores of limitation of physical function, the global assessment of disease severity, stiffness, and adverse events. Data given is on the intention to treat. Diaries were used to clarify the amount of rescue medication taken by each patient during the entire study period. The active group (rose hip powder) showed a significant decrease in pain after the initial 3 weeks of treatment: a WOMAC score delta reduction showed a $P$-value $<0.001$, whilst the placebo group shows no significant decrease $(P<0.299)$. After 3 months, however, no significant pain reduction was evident in either the placebo or the active group. The observation seems reasonable, as the patients after 3 weeks were instructed to reduce the amount of analgesics consumed whenever possible. And, indeed, a statistically significant reduction of more than $40 \%$ in the consumption of rescue medication was observed as the result of active treatment. It would have been interesting to see how large the decrease in the pain score had been, if patients had been instructed to keep consuming the same amount of pain relieving medications for the entire duration of the study.

After 3 months of active treatment, a significant reduction was detected in secondary parameters: stiffness $(P<0.037)$, limitation of physical function $(P<0.018)$, and patients' global assessment of disease severity $(P<0.035)$ when compared to placebo. The two groups were analyzed separately for carry-over effect. Group A (placebo first then active treatment) showed a significant improvement in limitation of physical function and in the global assessment of disease severity (PGAD).

The patients in group B (active treatment followed by placebo) showed a statistically significant reduction in pain, stiffness, and PGAD as a result of active treatment, although these changes did not return to the initial pre-treatment levels during the subsequent placebo treatment period, detailed in Table 1, ${ }^{11}$ suggesting a "carry-over" effect similar to what was observed in the Rein et al's ${ }^{10}$ study. This observation of carry-over effects associated with rose hip treatment indicates that the active ingredients may be lipid soluble, because such components have longer in vivo washout periods.

Side effects were very rare: two study subjects in each group reported incidences of diarrhea, while one in placebo
Table I The difference in clinical outcome from two different versions of rose hip powder, combined seed and shell and pure shell powder is given

\begin{tabular}{|c|c|c|}
\hline & Seed/shell & Shells \\
\hline $\begin{array}{l}\text { Effect on pain in placebo controlled RCT } \\
\text { trials }^{5,10-12}\end{array}$ & ++++ & - \\
\hline $\begin{array}{l}\text { Effect on stiffness in placebo controlled RCT } \\
\text { trials } s^{10-12}\end{array}$ & +++ & - \\
\hline $\begin{array}{l}\text { Effect on ADL in placebo controlled RCT } \\
\text { trials }^{5,10-12}\end{array}$ & ++++ & - \\
\hline $\begin{array}{l}\text { Patients' preferences to treatment in placebo } \\
\text { controlled RCT trials }{ }^{10}\end{array}$ & + & - \\
\hline $\begin{array}{l}\text { Patients' positive response rate in favor of } \\
\text { active treatment vs placebo } \\
10-12\end{array}$ & +++ & - \\
\hline Impact on symptoms of rheumatism ${ }^{5}$ & + & - \\
\hline Anti-inflammatory (from blood samples) ${ }^{5,29,42}$ & +++ & - \\
\hline Anti-inflammatory (from clinical observation) ${ }^{5}$ & + & - \\
\hline Dose-dependency ${ }^{42,44,45}$ & +++ & - \\
\hline Positive impact on cholesterol ${ }^{10}$ & + & - \\
\hline Meta-analysis $^{26}$ & + & - \\
\hline Effect size ${ }^{26}$ & + & - \\
\hline Reduction in rescue medication ${ }^{10,11}$ & ++ & - \\
\hline Protect from gastrointestinal damage $\mathrm{e}^{5,7,10-12}$ & + & $(+)$ \\
\hline Side effects ${ }^{5,10-12,33}$ & - & $(+)$ \\
\hline $\begin{array}{l}\text { Improvement on gait analysis (not tested } \\
\text { on "seed/shell" products) }\end{array}$ & - & + \\
\hline
\end{tabular}

Note: + Indicates positively reported and - indicates not reported.

Abbreviations: $A D L$, activity of daily living; $R C T$, randomized clinical trial.

and two in the active treatment group reported having constipation. One transient episode of urticaria was reported during active treatment. As in the earlier clinical studies, $5,10,11$ occurrences of side effects were very few and there were no differences when comparing incidences between active treatment and placebo groups. Moreover, all three studies demonstrated more flexibility of joints (less stiffness), improved daily function levels, reduction in pain levels, and amount of rescue medication taken with rose hip treatment.

Nonetheless, one of the limitations of the Winther et al clinical trial ${ }^{11}$ was that it focused on both reduction in pain and reduction of rescue medication at the same time. By so doing, the study subjects were reducing their intake of pain relief medication, while accessing their pain levels. It would have been interesting to know the magnitude of the reduction of pain scores without changing the consumption of rescue medication during the entire trial period. Future studies should take this described limitation into account in their design.

A meta analysis was performed on all randomized, placebo-controlled, double-blinded studies with rose hip treatment in the patients with OA, in order to estimate the empirical efficacy of rose hip as a pain reducing compound 
by calculating the ES. ${ }^{26} \mathrm{~A}$ group of 145 patients with osteoarthritis treated daily with $5 \mathrm{~g}$ of the Lito rose hip powder was compared to 142 patients on placebo. The ES for the rose hip powder was 0.37 (95\% confidence interval (CI): $0.13-0.60), P=0.002$. When focusing on responders on the yes/no basis, the results from the present placebo controlled studies were even more convincing, as it was more than two times more likely that patients on rose hip would respond to treatment. The finding of an ES of 0.37 for the Lito rose hip powder is interesting (refer Figure 2), especially when compared to the ES for paracetamol: 0.13 (95\% CI: $0.04-0.22$ ) or ES for glucosamine sulfate: 0.27 (95\% CI: 0.12-0.43). Other studies suggest that ES values for NSAIDs rarely exceed $0.40 .{ }^{26}$ A group of 145 OA patients as described in the present meta-analysis is not overwhelming. However, a broad summary, from the University of California, of the different effects of rose hip, state's an anti-inflammatory capacity of rose hip ${ }^{41}$ which is also in agreement with studies from Winther. ${ }^{42-45}$ In addition Winther's studies ${ }^{42-45}$ also shows dose dependency which, to the best of our knowledge, has never earlier been reported in more natural remedies against OA. A study on pain reduction after elective cesarean section using an extract from Rosa damascena further supports our conclusion. ${ }^{46}$

The Lito rose hip powder was recently tested in a low-dose setting of $2.25 \mathrm{~g}$ applied daily during a 3-month treatment period in a randomized, placebo-controlled parallel-design clinical trial. Sixty osteoarthritis patients were included in each arm..$^{42}$ One of the end points was to test if that low dose would have any impact on symptoms of osteoarthritis when evaluated using the WOMAC score system. It was shown that patients with a weight less than $84 \mathrm{~kg}$ benefited from the low dosage, whereas the heavier patients did not. In this study, a lowering of CRP was associated only with active treatment.

Next, another randomized, placebo-controlled and doubleblinded study was carried out to test the efficacy of $2.25 \mathrm{~g}$ mainly shell powder on patients with OA. ${ }^{43}$ Forty seven patients received a combination containing $90 \%$ shell and $10 \%$ seed product, while the remaining 47 participants recieved placebo. Pain and stiffness were estimated on a numerical scale from 0 to 10 . Quality of life was measured using SF-12 and CRP using normal laboratory routine. Pain and stiffness significantly declined as a result of active or placebo treatment, with no significant difference between the groups. There were also no significant changes in quality of life measurements and CRP levels remained unchanged in both the groups. It was concluded that the low dose of rose hip powder mainly consisting of shells does not alleviate symptoms of OA or exert detectable anti-inflammatory property in OA.

\section{Placebo-controlled and double-blinded clinical studies with rheumatoid arthritis patients}

Osteoarthritis is a result of wear and tear. By contrast, RA is a serious immune disease of joints, which also invokes inflammatory processes and can shorten life expectancy by several years. Hence, the efficacy of the rose hip treatment was evaluated in RA. A total of 89 patients were randomly assigned to treatment with either the Lito rose hip powder containing seeds and shells ( $5 \mathrm{~g}$ taken daily) $(\mathrm{n}=44)$ or placebo $(\mathrm{n}=45) .5$ The study design was parallel and apportioned to run for 6 months. The patients were tested initially and again after 3 and 6 months. Primary effect variable was Health Assessment Questionnaire (HAQ) disability index assessed after 6-month treatment. The HAQ-DI is derived from a questionnaire comprising eight subclasses of activities rated on a numerical scale. The HAQ also includes a patient's pain scale and a patient's global scale for the severity of the disease. Additional outcomes were: disease activity score (DAS-28), a combined index of swollen and tender joints, as well as erythrocyte sedimentation rate (marker of inflammation) and quality of life. Data were presented on the basis of intention to treat.

Treatment with rose hip resulted in a statistically significant improvement in the HAQ-DI score as compared to placebo after 3 and 6 months of treatment $(P<0.014$ and $P<0.032$, respectively). Significant changes or trends were not observed in any other parameter after 3 months of treatment. However, after 6 months of treatment, several parameters changed significantly: physical activity $(P<0.013)$, quality of life $(0.043)$ physician's global evaluations of patients' well-being $(P<0.012)$, and DAS-28 (0.056). Patients participating in the study for 3 months or more also showed a significant reduction in sedimentation rate (an inflammatory marker) and a similar decline, although not statistically significant, was seen for CRP. In accordance with inflammatory markers, the number of tender joints significantly declined when evaluating the per protocol population after 6 months. Therefore, the data present clear signs that the study subjects experienced substantial improvements from the third month of treatment and onward. Clinical trials on rose hip should possibly be of 6 to 12 months duration. The meta-analysis carried out earlier on 3-4-month trials possibly only show us "the tip of the iceberg". 
It is a known fact that many herbal remedies contain a certain amount of folic acid and that this vitamin can neutralize the beneficial effect of methotrexate. However, the present rose hip powder, when given in a daily dose of up to $5 \mathrm{~g}$ contains $20-30 \mu \mathrm{g}$ of folic acid. ${ }^{47}$ The recommended daily dose of folic acid from health authorities is $300-400 \mu \mathrm{g}$. Intake of $5 \mathrm{~g}$ rose hip powder daily is therefore not expected to negatively influence ongoing methotrexate treatment. ${ }^{48}$

Among the RA patients, side effects were few and not confined to active treatment. The GI disturbances were reported in five patients on active treatment and in eight study participants on placebo. Skin rashes and eczema were reported by two persons in the active and four persons in the placebo groups, respectively. Other side effects could not be related to treatment. Again, it seems that the combined seeds and shell powder of Lito rose hip is very well tolerated at the dosage of $5 \mathrm{~g} /$ day, even in studies running for 6 months. However, the Lito/RA study was not well powered but very promising and deserves a follow-up study.

\section{Dose-dependency with rose hip treatment}

In the Winther et al study, ${ }^{11}$ the patients with osteoarthritis were administered $5 \mathrm{~g}$ daily dosage of either rose hip powder or placebo and the body weight of the study subjects was in the range from 50 to $122 \mathrm{~kg}$. Consequently, the lower the body weight, the higher the dose of rose hip or placebo per kg. In principle, the lightest patients got approximately double the dose per kg body weight received by the heaviest study participant. When a correlation of weight vs symptom score on pain was made for the active treatment and placebo groups, there was a significant negative correlation between body weight and the reduction in pain scores only in the group treated with rose hip (correlation coefficient $-0.41, P$-value $=0.014$ ) after 3 months of treatment. ${ }^{44}$ The same observation was made in the rose hip study on patients with RA who were treated daily with $5 \mathrm{~g}$ of either rose hip or placebo for 6 months. ${ }^{45}$

The correlation coefficients of dose-dependency of rose hip and body weight were recently confirmed by data from the low dosage Lito powder testing in patients with osteoarthritis. ${ }^{42}$ The observation is of particular interest and provides proof that rose hip powder prepared from the seeds and shells is a reliable remedy for pain in osteoarthritis and also to some extent, RA. Indeed, the assessments of dosedependency, as outlined earlier, should be a routine strategy in clinical studies, for it strongly improves our knowledge of the investigational medicine, without adding more cost to the implementation of clinical trials.

\section{The latest addition to research on rose hip powders}

Ginnerup-Nielsen et al recently published the results of a randomized, placebo-controlled and double-blinded study, in which a pure rose hip shells-only powder was tested on 100 patients with OA of the knee. ${ }^{49}$ Study subjects were treated with $2.25 \mathrm{~g}$ of either placebo or shell-based rose hip powder daily for 3 months. Knee joint biomechanics during walking was assessed using three dimensional gait. A change from baseline to peak resultant knee moment was pre-specified as the primary outcome. Secondary outcomes were: self-reported KOOS for pain, symptoms, activities, knee related quality of life, as well as CRP inflammatory marker levels in blood samples. The group treated with rose hip showed more improvement in joint movements and knee flexion during walking than did the placebo group. As there were no changes in any of the KOOS symptom scores, reported by patients, or levels of the inflammatory marker CRP in the either test group, remarks cannot be made on any reduction in pain or other symptoms related to OA or any anti-inflammatory properties in this shell-based powder. So at present, the study seems very preliminary. However, biomechanical GAIT analysis is an objective analysis that is sensitive to changes in mobility limitations and allows for a detailed description of the biomechanical function of the knee at the knee joint level. ${ }^{50}$ Therefore, GAIT analysis may provide new information, at an early stage of osteoarthritis, and possibly be more sensitive and informative than patients self-recording of symptoms. Nonetheless, as the technology is new, the long-term clinical outcome of the measurement is still being debated. In addition, it is not clear what the magnitude of a GAIT response should be, before it is of clinical relevance. ${ }^{50}$ However, from the physicians' and patients' point of view the study is of limited interest as selfreporting on OA symptoms, including pain and inflammatory markers like CRP, by the patients remained unchanged. At the present dose, $2.25 \mathrm{~g}$ (three capsules) a day, the present shell-only based remedy does not seem to be relevant, and a similar powder was ineffective on inflammation markers at a dose of 40 g daily. ${ }^{51}$

At the Osteoarthritis Research Society International Congress 2015, there was a presentation of the results of a study showing that the rose hip powder based on seeds and shells alleviated pain and stiffness early in the morning as well as later in the day, when compared to placebo. ${ }^{52}$ The authors reported that this might explain why the combined seeds and shell rose hip powder has been reported to improve quality of sleep in patients with osteoarthrosis, ${ }^{10}$ 
because less pain during the night should improve the hours of deep sleep.

There was also a study in which the combined rose hip seed and shell powder was tested on the skin, which like cartilage, is known to be rich in collagen. The aim of the study was to use the skin of the face as a model for investigating the effect of rose hip on collagen support and protection. ${ }^{53}$ The authors were able to show that wrinkles of the face (crow feet) declined as a result of oral treatment with rose hip powder in the doses similar to those used for treating osteoarthritis. The authors suggested a positive impact of rose hip on skin collagen, ${ }^{54,55}$ and they also stated that rose hip seeds are rich in linoleic acid, which is a main constituent of the barrier function of the skin. ${ }^{55,56}$

Aqueous and more lipophilic extractions of rose hip have been tested in animal models with different results. , $^{2,13,18}$ To the best of our knowledge, there are no randomized, placebo controlled clinical studies on extractions from rose hip tested on humans. We found one open uncontrolled observational study in humans with osteoarthritis, who were given an aqueous extraction of rose hip added to collagen hydrolysate. ${ }^{57}$ The study indicated some improvement after 8 weeks of treatment. Although in vitro studies support the idea that rose hip extraction and collagen may work synergistically, ${ }^{58}$ it should be noted that there are, at present, no indications that this also takes place in vivo. And up until now there are no controlled clinical studies indicating that extractions of rose hip, with or without the addition of collagen hydrolysate, are effective against osteoarthritis in humans.

\section{Limitations}

The search went back to 1970 and restricted to English language papers. Author files were searched to further improve relevant papers. Research papers were extracted independently by the two researchers.

\section{Conclusion}

This review indicates that there has been a growing interest for the use of rose hip as an inflammatory agent within the last 2 decades. In summary, rose hip preparations have been shown to exhibit anti-inflammatory and antinociceptive (pain reducing action) properties in animal experiments. Furthermore, chronic or long-term administrations of rose hip do not result in the GI bleeding as is frequently observed with the use of ASA and NSAIDs. It is encouraging to note that the anti-inflammatory and the antinociceptive action of rose hip powder seems to vary from $50 \%$ to $100 \%$ of what is observed for ASA and NSAID. From testing different extractions of rose hip powder in experimental animal pain models, it was established that the lipid soluble fractions are the most promising, with regard to anti-inflammation and pain reduction properties. Further studies of the effects of rose hip preparations should be carried out by using the whole powder, as it has been done in the human studies. This is because the bioavailability of active components within the whole powder may be very different from what is observed by applying an extract. Interestingly, in the larger animal studies that were fed the whole powder, it was shown that the horses and dogs were more lithe the day after strenuous exercise, their fur looked better, and the animals tended to improve their speed during competition.

In general, the human studies can be looked upon as the studies performed with powders prepared from seeds and shells (the old version), and as studies performed with rose hip powders prepared from shells alone (the so-called new version). One such new shell-only powder has been designated "enhanced" with a so-called "complex". Nevertheless, it is not yet conclusively documented that the "enhanced new powder", is superior to the "old version" based on combined seeds and shells because the relevant single study was not properly blinded and showed an inverse dose-dependency.

In an earlier report, the shell-only powder was shown to have some impact on improving knee joint function, as GAIT analyses were reported to be in favor of such treatment in osteoarthritis patients. ${ }^{49}$ However, the combination of seeds and shells was not tested, and patients' evaluation of symptoms including pain as well as blood chemistry, defined as inflammatory markers, did not show any trends when comparing placebo and shell-based powder, making the study a little preliminary. ${ }^{49}$ By contrast, three other clinical studies reported a decline in blood levels of inflammatory markers during treatment with seeds and shell-based powder at the dosage $5 \mathrm{~g}$ daily. ${ }^{5,29,42}$ In another study where patients were treated with $40 \mathrm{~g}$ daily of pure rose hip shell-only powder, no change was observed in inflammatory markers. ${ }^{51}$ Hence, it would be surprising if the lower dosage of $2.25 \mathrm{~g}$ daily dose of "enhanced" shell-only based rose hip powder, recently introduced as a new remedy in osteoarthritis, would cause potent anti-inflammatory action. Only the clinical testing of rose hip preparations containing both seeds and shells has been supported by meta-analysis, ${ }^{26}$ as well as substantial anti-inflammatory activity. ${ }^{5,42,59}$ In the absence of suitable placebo-controlled randomized clinical trials, it seems too early to advocate for the use of rose hip powders based on rose hip shells alone in clinical settings, and the same holds true for the extracts. Besides, the results of the research involving in vitro screenings of rose hip powders, 
available so far, suggest that much of the anti-inflammatory properties of rose hip are contributed from the combination of seeds and shells/husks.

\section{Disclosure}

The authors report no conflicts of interest in this work.

\section{References}

1. Winther K, Campbell-Tofte J. Bioactive ingredients of rose hip (Rosa canina $\mathrm{L}$ ) with special reference to antioxidative and anti-inflammatory properties - in vitro studies. Botanics: Targets Therapy. 2015;5:1-13.

2. Deliorman Orhan D, Hartevioğlu A, Küpeli E, Yesilada E. In vivo anti-inflammatory and antinociceptive activity of the crude extract and fractions from Rosa canina L. fruits. J Ethnopharmacol. 2007;112:394-400.

3. Yeşilada E, Küpeli E. Berberis crataegina DC root exhibit potent anti-inflammatory, analgesic and febrifuge effects in mice and rats. J Ethnopharmacol. 2002;79(2):237-248.

4. Okun R, Liddon SC, Lasagna L. The effects of aggregation, electric shock and adrenergic blocking drugs on inhibition of the "writhing syndrome". J Pharmacol Exp Ther. 1963;139:107-109.

5. Willich SN, Rossnagel K, Roll S, et al. Rose hip herbal remedy in patients with rheumatoid arthritis - a randomized controlled trial. Phytomedicine. 2010;17(2):87-93.

6. Whittle BA. The use of changes in cappilary permeability in mice to distinguish between narcotic and nonnarcortic analgesics. $\mathrm{Br} \mathrm{J}$ Pharmacol Chemother. 1964;22:246-253.

7. Gürbüz I, Ustün O, Yesilada E, Sezik E, Kutsal O. Anti-ulcerogenic activity of some plants used as folk remedy in Turkey. J Ethnopharmacol. 2003;88(1):93-97.

8. Jäger AK, Eldeen IM, van Staden J. COX-1 and -2 activity of rose hip. Phytoher Res. 2007;21(12):1251-1252.

9. Jäger AK, Petersen KN, Thomasen G, Christensen SB. Isolation of linolenic and alpha-linolenic acids as COX-1 and -2 inhibitors in rose hip. Phytother Res. 2008;22(7):982-984.

10. Rein E, Kharazmi A, Winther K. A herbal remedy, hyben vital (stand powder of a subspecies of Rosa canina fruits), reduces pain and improves general wellbeing in patients with osteoarthritis - a double-blind, placebocontrolled, randomised trial. Phytomedicine. 2004;11(5):383-391.

11. Winther K, Apel K, Thamsborg G. A powder made from seeds and shells of a rose hip subspecies (Rosa canina) reduces symptoms of knee and hip osteoarthritis: a randomized, double-blind, placebo-controlled clinical trial. Scand J Rheumatol. 2005;34(4):302-308.

12. Warholm O, Skaar S, Hedman E, Mølmen HM, Eik L. The effects of a standardised herbal remedy made from a subtype of Rosa canina in patients with osteoarthritis: a double-blind, randomised, placebocontrolled clinical trial. Curr Ther Res. 2003;64:21-31.

13. Saaby L. Evaluation of immunomodulating and anti-inflammatory effects of a herbal remedy based on rose hip powder (rosa canina L.) $[\mathrm{PhD}$ thesis]. Faculty of Pharmaceutical Sciences, University of Copenhagen; 2011.

14. Woolfe G, Mac Donald AD. The evaluation of the analgesic action of pethidine hydrochloride (Demerol). J Pharmacol Exp Ther. 1944;80: 300-307.

15. Guardia T, Rotelli AE, Juarez AO, Plezer LE. Anti-inflammatory properties of plant flavonoids. Effect of rutin, quercetin and hesperidin on adjuvant arthritis in rat. Farmaco. 2001;56(9):683-687.

16. Ninomiya K, Matsuda H, Kubo M, Morikawa T, Nishida N, Yoshikawa M. Potent anti-obese principle from Rosa canina: structural requirements and mode of action of transtiliroside. Bioorg Med Chem Lett. 2007;17(11):3059-3064.

17. Nagatomo A, Nishida N, Fukuhara I, et al. Daily intake of rosehip extraxt edcreases abdominal visceral fat in preobese subjects: a randomized, double-blind, placebo-controlled clinical trial. Diabetes, Metab Syndr Obes. 2015;8:147-156.
18. Lattanzio F, Greco E, Carretta D, Cervellati R, Govoni P, Speroni E. In vivo anti-inflammatory effect of Rosa canina L. extract. J Ethnopharmacol. 2011;137(1):880-885.

19. Mills PC, Smith NC, Casas I, Harris P, Harris RC, Marlin DJ. Effects of exercise intensity and environmental stress on indices of oxidative stress and iron homeostasis during exercise in the horse. Eur J Appl Physiol. 1996;74(1-2):60-66.

20. Kirschvink N, Fiéves L, Bougnet V, et al. Effect of nutritional antioxidant supplementation on systemic and pulmonary antioxidant status, airway inflammation and lung function in heaves-affected horses. Equine Vet J. 2002;34(7):705-712.

21. Dimock AN, Siciliano PD, McIlwraith CW. Evidence supporting an increased presence of reactive oxygen species in the diseased equine joint. Equine Vet J. 2000;32(5):439-443.

22. Snow DH, Frigg M. Bioavailability of ascorbic acid in horses. J Vet Pharmacol Ther. 1990;13(4):393-403.

23. Winther K, Kharazmi A, Hansen ASV, Falk-Rønne J. A randomised placebo controlled double-blind study on the effect of subspecies of rose-hip (Rosa canina) on the immune system, working capacity and behaviour of horses. In: Ellis AD, Longland AC, Coenen M, Miraglia N, editors. The Impact of Nutrition on the Health and Welfare of Horses. Wageningen: Wageningen Academic Publishers; 2010. ISBN 978-90-8686-155-2.

24. Winther K, Kharazmi A, Hansen ASV, Falk-Rønne J. The absorption of natural vitamin $\mathrm{C}$ in horses and anti-oxidative capacity: a randomised, controlled study on trotters during a three-month intervention period. Complementary. Exer Physiol. 2012;8(3/4):195-201.

25. Winther K, Ragone A, Hansen ASV, Hansen P, Kharazmi A. A herbal remedy derived from subspecies of Rosa canina, improves the immune response, working capacity and well-being of dogs? A parallel, placebo-controlled, double-blind, randomized study. Osteoarthr Cartil. 2010;18(2):S149.

26. Christensen R, Bartels EM, Altman RD, Astrup A, Bliddal H. Does the hip powder of Rosa canina (rose hip) reduce pain in osteoarthritis patients? - a meta-analysis of randomized controlled trials. Osteoarthr Cartil. 2008;16:965-972.

27. Zang W, Robertson J, Jones AC, Dieppe PA, Doherty M. The placebo effect and its determinants in osteoarthritis: meta-analysis of randomized controlled trials. Ann Rheum Dis. 2008;67:1716-1723.

28. Winther K, Rein E, Kharazmi A. The anti-inflammatory properties of rose hip. Inflammopharmacology. 1999;7(1):63-68.

29. Kharazmi A, Winther K. Rose hip inhibits chemotaxis and chemiluminescence of human peripheral blood neutrophils in vitro and reduces certain inflammatory parameters in vivo. Inflammopharmacology. 1999; 7(4):377-386.

30. Chrubasic C, Weisner L, Black A, Müller-Ladner U, Chrubasik S. A one-year survey on the use of a powder from Rosa canina lito in acute exaderbations of chronic pain. Phytother Res. 2008;22:1141-1148.

31. Hochberg MC. Nutritional supplements for knee osteoarthritis - still no resolution. New Eng J Med. 2006;354(8):858-860.

32. Chrubasik-Hausmann S, Chrubasik C, Neuman E, Müller-Ladner U. A pilot study on the effectiveness of a rose hip shell powder in patients suffering from chronic musculoskeletal pain. Phytother Res. 2014;28(11):1720-1726. Doi:10.1002/ptr.5192.

33. Christensen R, Tarp S, Altman RD, et al. Comparing different preparations and doses of rosehip powder in patients with osteoarthritis of the knee: an exploratory randomized active-controlled trial. Int J Clin Rheumatol. 2014;9(3):267-278. doi:10.2217/IJR.14.13.

34. Wenzig EM, Widowitz U, Kunert O, et al. Phytochemical compositions and in vitro pharmacological activity of two rose hip (Rosa canina L.) preparations. Phytomedicine. 2008;15(10):826-835.

35. Roos EM, Lohmander LS. Knee injury and Osteoarthritis outcome Score (KOOS): from joint injury to osteoarthritis. Health $Q$ Life Outcomes. 2003;1:64.

36. Rodriguez-Merchan EC. Knee instruments and rating scales designed to measure outcomes. J Orthop Traumatol. 2012;13:1-6.

37. Woodworth T, Furst DE, Alten R. Standardizing assessment and reporting of adverse effects in rheumatology clinical trials. II: the rheumatology toxicity criteria v.2.0. J Rheumatol. 2007;34(6):1401-1414. 
38. Kirkeskov B, Christensen R, Bügel S, et al. The effects of rose hip (Rosa canina) on plasma antioxidative activity and C-reactive protein in patients with rheumatoid arthritis and normal controls: a prosepective cohort study. Phytomedicine. 2011;18(11):953-958. Doi:10.1016/j. phymed.2011.02.008.

39. Winther K, Campbel-Tofte J, Hansen P. Rose hip powder that contains the natural amount of shells and seeds alleviate pain in osteoarthritis of the dominant hand - a randomised, double-blind, placebo-controlled, cross-over clinical trial. Open J Rheumatol Autoimmune Dis. 2013;3:172-180.

40. Bellami N, Buchanan WB, Goldschmidt CH, Campbell J, Stitt LW. Validation study of WOMAC: a health status instrument for measuring clinically important patient relevant outcomes to antirheumatic drug therapy in patients with osteoarthritis of the hip or Knee. J Rheumatol. 1988;15:1833-1840.

41. Patel S. Rose hips as complementary and alternative medicine: overview of the present status and prospects. Mediterr J Nutr Metab. 2013;6:89-97.

42. Winther K. Low-dose seed and shell powder from rose-hip (Rosa Canina) can alleviate symptoms of osteoarthritis and reduce C-reactive protein in patients suffering from osteoarthritis (abstract). Osteoarthritis Cartilage. 2014;22(Supp1):S321-S322.

43. Winther K. Shells From Rose-Hip (Rosa Canina) Do not reduce symptom ccores or improve anti-inflammatory property in patients with osteoarthritis. A double-blind, placebo-controlled randomized study (abstract). Osteoarthritis Cartilage. 2014;22(Suppl):S321. ISSN 1063-4584.

44. Winther K, Hansen AS, Kharazmi A. A Dose-dependent impact of a standardised powder made from subspecies (Rosa canina) on WOMAC pain scores in patients with osteoarthritis of the hip and/or knee (abstract). Osteoarthritis Cartilage. 2009;17(1):S253 ISSN 10634584.

45. Winther K, Rossnagel K, Roll S, et al. A dose-dependent impact of a standardized powder made from subspecies of rose hip (Rosa canina) on HAQ pain score in patients with Rheumatoid arthritis (abstract). Ann Eur Cong Rheumatol EULAR, abstract no: 1554.

46. Gharabaghi PM, Tabatabei F, Fard SA, et al. Evaluation of the effect of preemptive administration of Rosa damascene extract on post-operative pain in elective caesarean sections. Af J Pharm Pharmacol. 2011;5(16): 1650-1955.

47. Strålsjö L, Alklint C, Olsson ME, Sjöholm I. Total folate content and retention in rosehips (Rose ssp.) after Drying. J Agric Food Chem. 2003;51(15):4291-4295.
48. Shea B, Swinden MV, Tanjong G, et al Folic acid and flolinic acid for reducing side effects in patients receiving methotrexate for rheumatoid arthritis. Codhrane Database Syst Rev. May 31, 2013;5:CD000951.

49. Ginnerup-Nielsen E, Christensen R, Bliddal H, Zangger G, Hansen L, Henriksen M. Improved gait in persons with knee related mobility limitations by a rosehip food supplement: a randomized double-blind placebo-controlled trial. Gait Posture. 2015;42(3):340-347.

50. Livine DF, Richards J, Whittle M. Whittle's Gait Analysis, 5th edition. 2012. Elsevier Health Sciences. Churchill Livingstone; 2012.

51. Anderson U, Berger K, Högberg K, Landin-Olsson M, Holm C. Effects of rose hip intake on risk markers of type 2 diabetes and cardiovascular disease: a randomized, double-blind, cross-over investigation in obese persons. Eur Journ Clin Nutr. 2012;66:585-559.

52. Winther K, Marstrand K. Circadian variation in symptoms of osteoarthritis - possible modification from treatment with seed and shell containing powder from rose hip (abstract). Osteoarthritis Cartilage. 2015:23(2):A169.

53. Phetcharat L, Wongsuphasawat K, Winther K. The effectiveness of a standardized rose hip powder, containing seeds and shells of Rosa canina, on cell longevity, skin wrinkles, moisture and elasticity. Clin Intervention Aging. 2015;10:1-8.

54. Schwager J, Hoeller U, Wolfram S, Richard N. Rose hip and its constituents galactolipids confer cartilage protection by modulating cytokine and chemochine expression. Complement Alt Med. 2011;11:105.

55. Schwager J, Richard N, Schoop R, Wolfram S. A novel Rose hip Preparation with Enhanced Anti-inflammatory and Chondroprotective Effects. Mediators Inflam. 2014. Article ID 105710,10 pages.

56. Elias PM, Brown BE, Ziboh VA. The permeability barrier in essential fatty acid deficiency: evidence for a direct role for linoleic acid in barrier function. J Invest Dermatol. 1980;74:230-233.

57. Feistel B, Walbroel B. A purified rode hip extract - effective in a new joint health concept. Z Phytother. 2012;33:10.

58. Schunck M, Oesser S. A combination of a specific collagen hydrolysate with a refined rose hip extract has a positive effect on the extra cellular matrix maintenance of cartilage cells. Ostearthritis Cartilage. 2010;18(Suppl 2):S245.

59. Larsen E, Kharazmi A, Christensen LP, Christensen SB. An antiinflammatory galactolipid from Rose hip (Rosa canina) that inhibits chemotaxis of human peripheral blood neutrophils in vitro. $J$ Nat Product 2003;7:994-995.
Botanics: Targets and Therapy

\section{Publish your work in this journal}

Botanics: Targets and Therapy is an international, peer-reviewed, open access journal focusing on the discovery and development of active compounds based upon or found naturally occurring in the plant kingdom that may have therapeutic potential in any disease state. The manuscript management system is completely online and includes a very

Submit your manuscript here: http://www.dovepress.com/botanics-targets-and-therapy-journal

\section{Dovepress}

quick and fair peer-review system. Visit http://www.dovepress.com/ testimonials.php to read real quotes from published authors. 